\title{
LABORATÓRIOS E DEVIRES MORAIS: EXPERIMENTOS PARA SE VIVER UMA BOA VIDA
}

\author{
Júlia Campos Clímaco \\ Universidade de Brasília
}

\section{Publicação}

MATTINGLY, C. (2014). Moral Laboratories: Family Peril and the Struggle for a Good Life. Oakland, California: University of California Press.

A autora Cheryl Mattingly é uma antropóloga norte-americana professora da University of Southern California e propõe, no livro Moral Laboratories: Family Peril and the Struggle for a Good Life, uma ética em primeira pessoa: ouvir como as pessoas narram e dão significados às suas vidas. É uma tentativa, portanto, de ver as pessoas como um feixe, como um ponto único no qual muitas histórias se cruzam: uma história que nos antecede, mas que nós continuamos. Um sujeito narrativo que narra suas histórias, suas experiências e trajetórias e nessas narrativas se constrói.

O livro, dividido em três partes, é uma etnografia sobre famílias negras, afro-americanas, muitas delas pobres, que vivem em bairros desprivilegiados e que cuidam de crianças doentes ou com deficiências. Essas famílias encaram uma série de tragédias ao longo de suas vidas e o interesse da autora é o de compreender, a partir de uma virtude ética e moral em primeira pessoa, como essas pessoas criam projetos morais para viver boas vidas, muitas vezes contrariando as estatísticas e a própria sorte (ou falta dela). Para isso, ela concentra seu olhar no cotidiano, nas tarefas mais corriqueiras, mas que podem trazer novidades, possíveis milagres.

$\mathrm{Na}$ primeira parte, a autora apresenta o ponto central de seu livro: os laboratórios morais vividos e criados no cotidiano (especialmente nos ambientes de casa, das clínicas e hospitais, da igreja e a rua) e a ética em primeira pessoa. A ênfase nas atividades cotidianas, singulares ou repetitivas, nos permite compreender como as decisões morais tomadas, em cada um desses momentos, não se referem apenas ao presente. Referem-se à rearticulação da vida presente, informada pelo passado, em constante ressignificação, e ao futuro, não apenas o futuro dado como certo, mas o que pode ser.

Já a ética em primeira pessoa é uma tentativa de ouvir como as pessoas se narram e dão significados às suas vidas, sem, com isso, acreditar em um indivíduo uno, autônomo, ou em um indivíduo dissolvido em redes de poderes. É ver as pessoas como produtos e produtoras de suas vidas, ver como fazem escolhas. Essas escolhas são restringidas pelas situações materiais e cotidianas, 
mas ainda assim, escolhas morais que podem criar novas vidas; que podem, inclusive, começar revoluções.

Essa parte se inicia com um desses laboratórios morais: um jogo de futebol no qual um menino com paralisia cerebral, Andy, vai jogar em sua cadeira de rodas e o dilema moral vivido pela sua mãe. Ela oscila entre a vontade de seu marido e de seu filho que ele jogue e seu próprio medo de que ele possa se machucar: vive, assim, o dilema de como encontrar o que é melhor para seu filho, ao mesmo tempo em que ela luta, cotidianamente, para que esse melhor para seu filho seja um conceito em constante expansão. A metáfora do laboratório nos remete a pessoas experimentando (real ou hipoteticamente), tentando e errando, mas tentando: são experiências arriscadas, mas que podem abrir possibilidades para outros mundos possíveis.

Nessa primeira parte, a autora nos apresenta o conceito de "projetos fundamentais" que ela usa como projetos morais tão profundos e constituintes que constroem as próprias narrativas de si. No caso das mulheres (e alguns homens) que conheceremos ao longo do livro, esse projeto fundamental parece ser o cuidado cotidiano com seus filhos/filhas/netos na tentativa de criar vidas que valham a pena serem vividas. Apresenta-nos, também, o conceito de "Mãe negra super-forte" fundamental para compreender o que vivem essas mães e avós: a necessidade e exigência de serem super mulheres negras para garantirem que seus filhos possam ter uma vida minimamente boa. Outro conceito central é o de devir moral: a moral não como um ser, mas como um vir a ser, um constante devir sem telos, sem finalidade dada, mas com fins possíveis, imaginados e "reimaginados", em uma constante reescrita de sua própria narrativa, em um processo de redimensionamento narrativo.

Ainda sobre as vidas minimamente boas, Cheryl Mattingly nos apresenta uma interessante discussão sobre os valores morais de bom e de bem: cada comunidade pode ter sua própria definição de bom e de bem, mas todas as comunidades têm alguma noção de bom e de bem e as pessoas agem em direção a ela. Suas vidas em direção ao bem e às vidas boas estão sempre ameaçadas pela tragédia e, para esse livro, é crucial a escuta de como essas mulheres vivem em meio à tragédia: a real e a potencial.

A segunda parte do livro é essencialmente etnográfica. Mattingly, com sua ética em primeira pessoa, apresenta as vidas de algumas famílias (em suas diversas configurações) e como elas, especialmente mães, vivem com crianças doentes e como vivem seus dramas, dilemas e tentativas de se criar novidades e boas vidas, para si e para seus/suas filhas.

A primeira família que conhecemos nessa parte é a de Delores e seu cuidado com Leroy, seu neto que nasceu com um problema ortopédico nos quadris, com mais quatro outros netos e com sua filha Marcy. Ela nos conta sobre como Delores resgatou a filha Marcy das ruas e como o cuidado com Leroy era um experimento, um processo de tornar-se para Marcy, para criar uma 
maternidade possível. Narra uma cena, bastante tocante, em que Marcy está na sala de fisioterapia de Leroy, mas sem interagir nem olhar para o que se passa: ela está ali como pode, nesse momento. E só quem sabe da importância dessa presença silenciosa parece ser Marcy e Delores: ambas compreendem que Marcy está recriando uma possibilidade de maternidade.

A história dessa família é central para compreendermos a importância que a autora atribui aos elementos cotidianos da vida, pois relata que quando perguntada sobre os desafios de sua vida, Delores respondia com uma narrativa repetitiva sobre seu dia-a-dia. E parece ser nessa repetição que os novos mundos possíveis podem existir, é no cuidado cotidiano, no olhar o outro, na relação que se estabelece justamente na repetição da presença.

O segundo drama que vivemos com o livro é o de Sasha - filha de Delores - e seu filho Willy. Nessa mesma casa onde vivem Delores, Marcy, seus cinco filhos, vivem também Sasha e Willy e em um acidente doméstico que envolveu uma das filhas de Marcy, ele sofre uma grave queimadura que muda sua vida, a de sua mãe, e a de todos/as da casa. Sua mãe, aspirante a bailarina, se vê obrigada a lidar com um novo presente e futuro, nos quais ela é mãe de uma criança que corre risco de vida e, depois, gravemente marcada pelas queimaduras. Sasha busca, então reescrever sua vida com essa nova maternidade, em uma tentativa de estar apta ao novo desafio que lhe foi apresentado, como a autora afirma no início do livro: o que interessa é como essa mulher pode lidar com a tragédia. Mattingly nos conta como o processo de tornar-se para Sasha e para Delores foram por vezes conflitantes. A tentativa de Sasha, no experimento de vislumbrar possibilidades boas de vida para seu filho, era a de super-valorizar suas qualidades, de torná-lo um menino singular, apesar de suas cicatrizes. Já a de Delores era, justamente, o de vê-lo com um menino ordinário, como um menino que, com suas cicatrizes, vive a vida da casa como e com os outros, enfrentando o preconceito e sabendo como contorná-lo.

O próximo dilema moral que acompanhamos é o de Dotty com sua filha Betsy, que sofre de anemia falciforme grave. Essa mãe se viu obrigada não apenas a cuidar da saúde de sua filha, mas a entrar em constantes embates com o corpo médico, para que oferecessem o melhor tratamento possível para Betsy. Dotty aprendeu muito sobre a doença da filha e seu tratamento, mas também sobre como lidar com os médicos e enfermeiras, para conseguir ser assertiva o suficiente para ser ouvida em suas demandas, mas não demasiadamente assertiva de modo que pudesse ter problemas com a equipe médica. Entretanto, ela vive um dilema de ter se envolvido tanto com o cuidado da doença da filha, com seu corpo doente, que teme ter perdido de vista sua filha: teme ser muita mais uma cuidadora da filha do que sua mãe. Assim, o seu devir moral é encontrar um balanço entre ser essa supermãe lutadora para sua filha doente e também uma mãe acolhedora e afetuosa para uma filha. 
Em seguida, conhecemos a história de Andrena e sua filha Belinda, que foi diagnosticada, aos quatro anos de idade, com um câncer no cérebro bastante sério. A autora narra a evolução médica de Belinda desde o diagnóstico, com seus piores e melhores momentos. Entretanto, o que me parece mais interessante nesse capítulo é como ela narra o experimento moral de sua mãe: ao mesmo tempo em que ela luta, todos os dias, quase sozinha, para que sua filha sobreviva e tenha uma boa vida, ela projeta e imagina futuros onde a filha estará morta e ela sozinha. Ficamos com a sensação de que ela está sempre transitando em dois mundos, um no qual sua filha vive e outro no qual ela não mais vive. E ela transita cotidianamente por esses mundos, como podemos ver por dois momentos narrados no livro: sua festa de aniversário de cinco anos, que foi comemorada como sua filha desejava e como ela mesma o desejava, "como se" ela fosse uma criança normal comemorando apenas mais um aniversário entre outros; e o seu funeral e enterro, que tinha sido cuidadosamente planejado de antemão para que fosse uma celebração de sua vida e de sua vida futura, pós-morte: teve balão, crianças correndo, música e outros túmulos de crianças para que ela nunca estivesse sozinha.

Já na terceira parte, a autora narra como um pluralismo moral pode causar revoluções: narra a visão conflitante que Darlene e Andrew, pais de Arlene, tinham da sua vida ligada a máquinas e medicamentos como um milagre divino e como sua equipe médica-hospitalar, partindo de outro campo moral, a via não como vida natural, mas como uma vida forçadamente prolongada para e pelos seus pais. Para a autora, não havia conciliação possível, pois cada pólo se referia a um tipo de bebê específico. Entretanto, na convivência forçada desses dois pólos, esse bebê também pode ser um só, transitando pelo seu corpomáquina, como descrito pelos médicos, mas também pela mãe, e pela sua existência singular como filha de um casal religioso, amoroso e atento.

Por último, Mattingly retoma o que já nos havia anunciado no começo do livro: esse não é um livro de finais felizes. Narra o que sabe, até o momento da publicação do livro, sobre cada uma dessas famílias e sobre as novas tragédias que se abateram sobre eles. Só podemos, então, imaginar que novos experimentos os e as levaram a novas experiências de novas possibilidades de mundo.

\section{DECLARAÇÃO DE CONFLITOS DE INTERESSE}

Não há conflito de interesses. 
Sobre a autora

Júlia Campos Clímaco é psicóloga pela Universidade de Brasília, mestra em Ciências Sociais e Educação pela Facultad Latinoamericana de Ciencias Sociales, Sede Argentina, e doutoranda Programa de Pós-Graduação em Processos de Desenvolvimento Humano e Saúde pela Universidade de Brasília. Trabalha na linha Psicologia Cultural, nos temas: estudos da deficiência, direitos humanos, gênero e feminismo. juliaclimaco@gmail.com

Recebido em: 09/09/2017

Aceito em: 18/09/2017 